\title{
OH! E AGORA? QUEM PODERÁ NOS DEFENDER? LUKE CAGE, O HERÓI DE ALUGUEL
}

\author{
Oh! what now? who may defend us? Luke Cage, the rental hero
}

\author{
Sonia Maria Gomes SAMPAIO \\ Universidade Federal de Rondônia \\ soniagomesampaio@gmail.com \\ Mara Genecy Centeno NOGUEIRA \\ Universidade Federal de Rondônia \\ maracenteno@gmail.com
}

\begin{abstract}
RESUMO: O presente artigo tem por objetivo investigar e/ou interrogar, à luz das teorias do Pós-colonialismo, o protagonista negro das histórias em quadrinhos (HQs) da Marvel, dos anos de 1970 ou mais precisamente, Luke Cage - o herói de aluguel ou o herói às avessas. Partindo-se do pressuposto que os personagens negros da história em quadrinho eram quase sempre colonizados, estereotipados e/ou apresentados na condição de coadjuvante e subalternos, pretendeu-se por meio da análise do herói de aluguel, em sua trajetória, identificar os traços que o distingue dos demais personagens negros como resistência e luta pelo enaltecimento da cultura negra. Para desenvolver tal investigação a pesquisa dialogou com Frantz Fanon (2008; 1968), Albert Memmi (1977), Kabengele Munanga (1988), Gayatri Spivak (2010) Chimamanda Adichie (2009). PALAVRAS-CHAVE: Luke Cage; Histórias em Quadrinhos; Super-heróis; Pós-Colonialismo.
\end{abstract}

\begin{abstract}
In this article, we aim at investigating and/or interrogating, under the light of postcolonial theories, the black protagonist from Marvel Comics (comic books) of the 1970s. More precisely, we intend to explore Luke Cage - the hero in reverse. Based on the premise that the black characters of the comic strip were more often than not colonized, stereotyped and / or presented as coadjutant and subaltern, we proposed analyze the renting hero, in his trajectory, to identify the traits that makes him different from the other black characters: such as resistance and the struggle for the enhancement of the black culture. In order to develop our study we got the theoretical support from Frantz Fanon (2008; 1968), Albert Memmi (1977), Kabengele Munanga (1988), Gayatri Spivak (2010) Chimamanda Adichie (2009) among other postcolonial thinkers.
\end{abstract} KEYWORDS: Luke Cage; Comics; Super heroes; Post-Colonialism. 


\section{INTRODUÇÃO}

O século XX foi embalado por significativas mudanças políticas, sociais e econômicas. Neste século foram desencadeadas duas grandes guerras mundiais, a primeira de 1914 a 1918, a segunda de 1940 a 1945; e nesse contexto foi possível visualizar as seguintes questões: instituições e países vencedores e perdedores, enaltecimento de intolerâncias de várias ordens, sobretudo, as de cor e de religião, a grande crise mundial ocasionada pela quebra da bolsa de valores de Nova York em 1929, além de ter demarcado, dentre outras mudanças, a reivindicação de vários grupos sociais, até então marginalizados, que passaram a exigir direitos civis (HOBSBAWM, 1995).

Foi nesse cenário de transformações que as histórias em quadrinhos, doravante denominadas de (HQs), começaram a criar e apresentar, principalmente a Marvel, uma série de super-heróis, tais como: Capitão América, Homem Aranha, Super Homem, Quarteto Fantástico, Pantera Negra, Luke Cage dentre outros heróis e heroínas que ilustraram as HQs visando salvar o mundo ou simplesmente salvar o homem comum, inclusive de si mesmo.

O objetivo deste artigo é investigar e/ou interrogar, a luz das teorias do Póscolonialismo, o protagonista negro das HQs da Marvel denominado, Luke Cage - o herói de aluguel. As nossas interrogações de pesquisa foram: Por que os primeiros personagens negros eram estereotipados ou então precisavam aparecer ao lado de super-heróis brancos? Por que o continente africano era representado na maioria das HQs em um quadro de distopia? Por que o protagonista negro era um herói de aluguel? O que levou a Marvel a criar tal personagem?

A pesquisa em tela procurou, em um primeiro momento, apresentar os primeiros personagens negros das HQs, contextualizando-os historicamente. Fazermos tal percurso nos levou para além das visões estereotipadas atribuídas, inicialmente, aos negros e ao Continente Africano, e a percebermos, também, o barulho por baixo da história ou mais precisamente a entender o contexto da criação de super-heróis negros.

A segunda parte da investigação procurou focar na análise do Luke Cage, narrando um pouco de sua trajetória até chegar à condição de herói e protagonista negro. Podemos dizer que analisá-lo à luz dos pensamentos do Pós-colonialismo nos proporcionou percebê-lo na condição de um herói às avessas, a concebê-lo com um grande expoente da cultura black power e como um dos maiores representantes dos negros nas HQs, uma vez que suas narrativas ajudaram a combater complexos atribuídos aos homens e mulheres de cor. 
Esperamos que as narrativas e as aventuras de Luke Cage possam contribuir para enaltecer as histórias em quadrinhos na condição de fonte e que possam ainda inferir, ao nosso leitor, que os personagens negros serviram para expor as injustiças provocadas pelo colonialismo e a denunciar as contradições e conflitos vivenciados, sobretudo, pelo viés da intolerância.

Boa leitura!

\section{ENTRE RABISCOS E TRAÇOS: CONTEXTUALIZANDO ALGUNS OS PERSONAGENS NEGROS ANTERIORES A LUKE CAGE}

A década de 70, para os negros norte-americanos, revelou uma série de conquistas resultante dos anos 50 e 60, em que várias ações ditas afirmativas, foram adquiridas com muita luta pelas comunidades negras estadunidenses. Dentre essas conquistas podemos citar: Ato do Direito ao Voto ocorrido em 1965; criação do Programa de Igualdade de Oportunidades; medidas de combate ao racismo e ofertas de oportunidades aos negros e outras minorias (mexicanos, indígenas, latinos). Um exemplo de luta pode ser extraído da história de Rubi Bridges, menina negra de seis anos que por meio da ação impetrada por seus pais, conseguiu romper, em 1960, com o paradigma de que negros não podiam estudar ao lado de brancos. Rubi foi matriculada na escola Willian Frantz na cidade de New Orleans e para manter o seu direito adquirido chegou à escola escoltada por agentes federais, além de enfrentar protestos de toda ordem.

Porém, apesar das conquistas, a década de 70 transbordou incertezas para os negros afroamericanos. Tais incertezas foram desencadeadas, sobretudo, a partir de 1968 com o assassinato de Martin Luther King e pelo ódio do branco que entendia a ascensão de negros na política, na Universidade e em outros programas governamentais como franca ameaça aos seus interesses. A partir daí, o que se evidenciou foram sucessivas ondas de ataques e segregações raciais, porém a luta pelos direitos civis dos negros no país não cessou. Manifestos surgiam de toda ordem e em vários formatos, com discursos e expressões culturais voltadas para a valorização da cultura negra.

Os anos 70 também foram marcados por divisões sociais, raciais e políticas que ensejaram luta por liberdades em todos os sentidos. Os negros norte-americanos, engajados em movimentos como os da Liga Revolucionária de Trabalhadores Negros, organizavam-se, por exemplo, para lutar por melhores condições de trabalho e contra o racismo. O movimento político e religioso denominado de Nação do Islã, liderado por Malcolm X, somadas as ações desencadeadas pelo Partido dos Panteras Negras, que já 
tinham notoriedade desde a década anterior na luta contra o racismo, ganham ainda mais força por meio dos ideais desencadeados pela cultura black power que enaltecia o poder e o orgulho de ser negro.

Cabe-nos salientar que a cultura black power surgiu embalada não só por lutas por direitos civis, mas por meio de eventos provenientes dos anos 60 como o festival de música de Woodstock, acontecido na cidade de Bethel, no estado de Nova York, entre os dias 15 e 17 de agosto de 1969, que se transformou em ato político reverberado nas letras das músicas, na liberdade e rebeldia dos participantes do referido festival. A contracultura é expressamente difundida neste festival por meio de manifestações contra a Guerra do Vietnã, qualquer tipo de opressão e a favor da liberação sexual.

Embalados por canções que falavam de um mundo melhor, os jovens pensavam uma forma de viver mais harmônica, mas também não deixavam de resistir. No festival de Woodstock os hippies com suas roupas coloridas, com flores na mão e praticamente sem preconceitos se encontraram com alguns expoentes da música e suas canções que ecoam até hoje, como: Jimi Hendrix, Janis Joplin, Joe Cocker, Carlos Santana, Joan Baez, Ravi Shankar, mas Bob Dylan não pode ser visto, posto que recusou o convite para participar do festival. À parte ser um festival de rock, Woodstock, foi um momento em que jovens negros e brancos se aproximaram, além de expor para o mundo, músicas de ritmos variados como o blues, soul, jazz e folk que são marcadamente representantes da música negra americana com raízes e identidades ancestrais dos batuques e lamentos de África.

Sendo assim, todos os movimentos culturais vivenciado nos anos 60 contribuíram para que jovens negros tivessem orgulho da cor da pele, dos cabelos, do colorido das roupas e dos acessórios corporais que ajudaram na formação identitária de negros e negras que experenciavam os guetos de várias cidades dos Estados Unidos, como infere Karnal (2007, p. 247-48):

Movimentos 'black power' (poder negro) emergiram na segunda metade da década no encalço de Malcolm X, combinando 'nacionalismo cultural' (que valorizava tradições afro-americanas) e luta militante contra a discriminação racial. O Partido dos Panteras Negras, fundado por universitários negros na Califórnia em 1968, apelou para a 'autodefesa armada' contra policiais racistas e fez alianças com progressistas brancos contra a guerra, a exploração e a opressão social de todo o tipo. Os panteras ganharam bastante popularidade nos bairros negros das cidades grandes com sua 'política de orgulho negro', sua propaganda militante e seus programas de assistência social voltados à comunidade. Um relatório do FBI elaborado em 1970 relata que " $25 \%$ 
da população negra tem grande respeito pelos panteras negras, incluindo $43 \%$ de negros com menos de 21 anos de idade". Justamente por causa dessa popularidade ampla, a organização foi esmagada brutalmente, entre 1969 e 1971, pelo FBI com muitos dos seus líderes assassinados ou presos em ações policiais.

Foi nesse cenário de luta e de efervescência cultural que a Marvel criou, em 1972, a revista em quadrinhos protagonizada por um negro - Luke Cage. Tal personagem não foi o primeiro negro das histórias em quadrinhos - HQs, uma vez que antes dele a indústria de gibis já havia criado personagens secundários que ilustravam as páginas das HQs que percorriam o mundo. Os primeiros registros de personagens negros nas histórias em quadrinhos eram apresentados com lentes que geravam visões estereotipadas, na maioria das vezes eram coadjuvantes e representados em condições de subalternidade. Eram considerados personagens cômicos, com olhos esbugalhados, lábios grossos totalmente caricaturados (HARRIS, 2003).

No tocante à apresentação caricatural de homens negros, como feios, beiçudos e de olhos esbugalhados não é uma novidade, é uma prática constante que remonta aos tempos do descobrimento de alguns países e muito típico nos processos de colonização praticados pelos europeus. O exemplo disso pode ser visto no poema de Rudyard Kipling intitulado "The White Man's Burden" (O fardo do Homem Branco), publicado em uma revista de Nova York, McClure's, em 1899.

O poeta Kipling nasceu em Bombaim, na Índia colonizada pelos britânicos, e embora tivesse consciência da violência e crueldade praticadas pelos colonizadores sobre suas colônias, tentava amenizar e justificar esse comportamento brutal em nome de uma suposta bondade do colonizador em expandir a dita civilização, que incluía práticas da religião cristã, gostos alimentares iguais ao do homem branco e processos higienizadores para os que não eram europeus, ou seja, para aqueles que eram pertencentes as culturas diferentes, julgadas em atraso,

O retrato de homens não europeus trazido pelo referido poeta era de que homens de outros lugares seriam selvagens ou um misto de seres esdrúxulos "metade demônio, metade criança", portanto feios, como referenciado em seu poema,

Tomai o fardo do homem branco -

Envia teus melhores filhos

Vão, condenem seus filhos ao exílio

Para servirem aos seus cativos;

Para esperar, com arreios

Com agitadores selváticos 
Seus cativos, servos obstinados

Metade demônio, metade criança

(Kipling, 1899, p.17)

O fardo do homem branco, segundo Kipling, apresenta-se como o esforço hercúleo de colaborar para a civilização de "tristes povos" que viviam em outras regiões do planeta à margem do que ele considerava ser o melhor dos mundos, o mundo europeu.

Nas HQs, os primeiros a romper um pouco com tais estereótipos foram os personagens Lothar e Waku. O primeiro produzido inicialmente pela editora Dell Comics foi personagem coadjuvante da revista do mágico Mandrake (1934), apesar de ser herdeiro de uma confederação tribal resolveu largar o seu lugar de destaque para acompanhar o mágico em suas andanças mundo afora. O segundo, Waku, surgiu em 1954, na condição de herói que lutava pela libertação do povo Bantu, em um gibi que recebia o seu nome e que era produzido pela editora Timeley/Atlas. No entanto, apesar dos personagens serem retratados com mais seriedade pelos seus produtores, ambos carregaram a marca que a indústria cultural queria emblematizar a respeito da África e dos seus habitantes. Em Waku, o continente africano é representado como hostil e recheado de guerra entre tribos e com Lothar encontramos uma das grandes marcas do colonialismo que era a de transformar os negros em obedientes e seguidores dos colonizadores, como fez o assistente do mágico.

Temos, por meio destes personagens, visões de África completamente distorcidas, criadas a partir de diretrizes europeias cujas características se delineavam a partir de enfoques que apresentavam as populações vivenciando a barbárie e, consequentemente, fora da lógica capitalista, uma vez que não apresentavam um fluxo significativo de mercadorias e serviços que lhe possibilitasse adentrar na rota do desenvolvimento. As dinâmicas implementadas no processo colonizador ao continente africano ainda se retratavam nos gibis, com personagens ainda caricaturados na barbárie, como no caso de Waku, ou na condição de subalternidade e/ou de 'bom selvagem', em relação a Lothar, demonstrada em vários números e episódios da revista de Mandrake.

O próximo personagem negro de destaque surgiu em 1966. Seu nome? Pantera Negra. Criado por Stan Lee e Jack Kirby, tem seu registro de nascimento relacionado ao período de agitação racial desencadeados pelos discursos voltados à ampliação dos direitos civis e antirraciais promovidos por Malcolm X, Martin Luther King e pelo Partido dos Panteras Negras.

Apesar de ter sido criado como super-herói negro nas HQs da Marvel, o Pantera não teve inicialmente uma revista só sua. Sua aparição se dava em gibis de outros 
protagonistas como o Quarteto Fantástico, Capitão América, Vingador, dentre outros. Tal situação só veio a mudar a partir de 1998 quando Christopher Priest (escritor/editor negro) assumiu a trajetória do Pantera Negra e o colocou na condição de protagonista criando uma revista só pra ele.

É importante fazermos um parêntese para frisarmos a trajetória de Priest, pois foi ele que conduziu, não só a transformação do Pantera Negra à condição de protagonista das HQs, como foi, ao lado do afroamericano Billy Graham, um dos responsáveis pelo sucesso de Luke Cage. Perceber o percurso do escritor negro ajudará na compreensão dos personagens que ele ajudou a alavancar nas HQs.

James Christopher Owsley ou simplesmente Christopher Priest, como passou a ser chamado após a mudança de nome na década de 90, entrou para indústria dos quadrinhos em 1978 na condição de estagiário, teve seu talento descoberto ao atuar nas HQs de Conan, porém a visibilidade foi garantida na Marvel, ao desenvolver o que poderíamos chamar de Blaxploitation dos quadrinhos (a expressão é do cinema, mas serve para evidenciar o que queremos enaltecer), que é a presença de negros na condição de protagonistas das HQs, primeiramente com o Pantera Negra e depois com o Luke Cage.

Quando Priest assume a revista do Pantera Negra, a trajetória do personagem estava associada a uma África já um pouco diferente da retratada nas HQs do Waku do Lothar, porém ainda recheada de estereótipos. O continente africano apresentado nas narrativas do Pantera insinua uma nação fictícia, Wakanda (África Oriental), que tem como fonte de sua principal riqueza um metal também fictício - vibranium, adquirido através da queda de um meteorito na tribo de T'Challa, que é o nome legítimo do Pantera Negra.

É em torno de tal riqueza e de sua defesa que surge o super-herói. Na tentativa de resguardar tal recurso, capaz de absorver a energia cinética, $\mathrm{T}^{\prime}$ Challa foi estudar nos Estados Unidos e se tornou um cientista. A força, a agilidade e velocidade adquirida pelo personagem também vem de fora, uma vez que é resultante do chá da Erva em Formato de Coração que faria parte do ritual de celebração de sua coroação na condição de rei de Wakanda; a referida erva era resultante de uma planta alterada pela radioatividade do vibranium, portanto, também exógena.

Como podemos perceber, para consagrar um super-herói negro, os mecanismos encontrados foram todos endógenos. Algumas análises sobre o Pantera Negra destacam o avanço tido no campo da representação da África como um continente já desenvolvido e em harmonia até a chegada do homem branco ou do grande vilão e/ou arqui-inimigo do Pantera, Ulisses Klaw. 
Nisto apontamos que apesar do Pantera Negra ter tido destaque nas HQs o superherói não deu conta, pelo menos inicialmente, de apresentar uma narrativa que deixasse transparecer as lutas por direitos civis travadas pelos negros. Ao contextualizá-lo como uma figura exógena, seus criadores acabaram por condená-lo ao papel secundário e obscuro, uma vez que não dialogava com os anseios políticos e sociais dos negros norteamericanos.

Inserir um personagem negro descontextualizado do panorama político da década de 60, estigmatizou ainda mais o Pantera Negra, tendo em vista que ele foi colocado lutando pelos ideais do branco e ao lado de outros super-heróis, também brancos e responsáveis por reforçar os interesses dominantes, deixando a margem e/ou periferia os negros.

Observa-se ainda que a roupa do Pantera Negra, escondia muito mais do que a sua identidade, escondia a sua cor e, consequentemente, a luta contra o racismo. O super-herói nasce encoberto pelo manto da invisibilidade que a sociedade norte-americana queria garantir aos negros. Encobri-los significava também negá-los o direito de fazer parte da construção de uma América predominantemente branca e hegemônica que aniquilava histórias locais, direitos a todos e segregava grupos em nome de uma limpeza racial velada.

Ao criar o personagem, a Marvel não agregou valores que poderiam ter quebrado com os graus de subalternidade garantidos aos negros; não agregou discursos pela libertação das colônias africanas que estavam sob o jugo europeu e nem tampouco denotou traços contra a política imperialista e ao racismo. Assim, podemos inferir que o universo dos quadrinhos atribuído ao Pantera parece não coadunar com a defesa ou proteção dos seus irmãos de cor e a não revelar a trajetória de condenação a que foram relegados. Tal situação mudou e viria a passar por um processo de transformação a partir de 1998, ou seja, mais de trinta anos depois do surgimento do Pantera por meio das HQs, sob a criação de Christopher Priest, como inferido anteriormente, que insere no referido personagem conflitos existenciais que o fazem se voltar para as causas mais sociais e assumir o protagonismo que um rei e um super-herói negro requeriam.

A partir do final da década de 90 a trajetória do primeiro protagonista negro das HQs não negava mais a sua cor, seus semelhantes e nem o seu continente. A nova trajetória mostrava um personagem mais focado em deslocar a visão do leitor para os problemas vivenciados pelos negros norte-americanos e a apresentar uma África para além da visão romântica de símbolo de pureza e inocência. 
Priest revela ao leitor muito mais que um personagem de cor, revela-nos os bastidores de uma indústria de HQs, ou mais precisamente a Marvel, que buscou nos personagens negros, a construção de uma narrativa muito mais humana e com eles se salvar de uma grande crise financeira e nesse sentido, o escritor negro (Priest) foi fundamental.

\section{LUKE CAGE, O HERÓI DE ALUGUEL}

O personagem Carl Lucas nasceu no bairro do Harlem, na periferia de Nova York, e como muitos adolescentes se envolveu em várias confusões, particularmente com gangues. Após várias passagens pela polícia resolveu se regenerar, porém seu amigo de infância e de confusão - Willis Stryker - continuava a enveredar-se nos mesmos caminhos de erros, apesar dos conselhos de Lucas.

O enredo para a construção do herói se processa justamente nesse cenário de regeneração. A namorada do amigo, Reva Connors, decepcionada com o universo criminoso em que Willis ainda insistia em permanecer, resolveu buscar abrigo nos braços de Carl Lucas e em um dos encontros, Willis os ver juntos e resolve armar uma armadilha para o amigo de infância. Assim, drogas são inseridas no apartamento de Lucas e novamente ele é preso.

Tal desfecho, fez com que dessa vez Carl Lucas se sentisse injustiçado. Na prisão passou a se envolver em uma série de atritos que o levou várias vezes a solitária, o que causava reação brutal por parte dos guardas que não entendiam que toda a revolta era a forma de expressar a sua dor por ter causado decepção na família e amigos mais uma vez.

Entre as passagens pela solitária e inúmeras brigas, Cage acaba aceitando a proposta de um cientista - Dr. Burnstein - que estava na prisão recrutando apenados para serem cobaias em um experimento que aumentava a massa muscular e, consequentemente, a força. No momento em que Carl Lucas estava para iniciar os procedimentos, um dos guardas que não gostava dele acabou sabotando a máquina e alterando o processo cujo resultado foi a presença inexplicável de uma super força e um corpo impenetrável por bala e armas brancas.

Com os novos poderes o herói foge da prisão e vislumbra sobrevivência voltando ao mundo do crime, porém desiste no último instante e, mais tarde percebe que pode oferecer seus serviços em troca de dinheiro. É nesse cenário que nasce Luke Cage - o herói de aluguel. 
Cage surge com a cara lavada, ou seja, não se utiliza do artifício nem de capas e nem de máscaras para the causar invisibilidade. O personagem reforça a cultura Black Power, presente no estilo de roupas e de cabelo, que o colocam na condição de mais um na multidão. Ser um negro como outro qualquer, o fazia passar desapercebido. É um personagem humano, pois ao logo das narrativas o leitor percebe suas dores e o quanto ele lutou para se tornar melhor e não magoar aos que amava. Para além disso, suas narrativas apresentam os guetos norte-americanos dos anos 70 e revelam que a política vinculada aos direitos civis ficou muito mais nos discursos, tendo em vista que a maior parte da população negra continuava marginalizada. E nesse sentido, Luke Cage, revela-nos um empoderamento do negro, uma vez que não se esconde e nem tampouco assume uma postura de subalternidade perante o branco. Suas histórias revelam as mazelas dos crimes presentes entre os dois mundos, ou seja, de negros e brancos.

Seria ele um herói ou um anti-herói? Afinal, as suas práticas são moralmente questionáveis. Cage em nossa opinião se encaixa muito bem na condição do anti-herói, tendo em vista que transita por caminhos que nem sempre o elegeriam à condição heróica, uma vez que vende a sua super força a quem possa pagar.

Como infere Brombert (2014), os anti-heróis não são fracassados, pelo contrário, são personagens, como todos nós, que de certo modo apresentam sem máscaras nossos medos e levantam os preconceitos sociais. Nesse contexto, Luke Cage se encaixa perfeitamente em tal descrição, pois se apresenta como um transgressor e/ou como um "contramodelo" que contesta a ordem estabelecida. É o negro que congrega o elemento da super força e de um corpo a prova de balas, mas que não se esconde por meio de capas ou máscaras.

As HQs de Luke Cage revelam, nas entrelinhas, a inconformidade com o discurso colonizador e tais traços vão se manifestando na valorização cultural, nos costumes, no modo de vestir e de ser, que acentuam não haver uma crise de identidade, pelo contrário, há valorização dos traços culturais e rejeição ao que era fabricado pelo universo dos brancos.

O herói de aluguel não repetia as características atribuídas aos negros no processo de colonização e nem tampouco as que ainda estavam presentes em muitos enunciados brancos nos anos 70 nos Estados Unidos “[...] Vestidos à europeia, de terno, óculos, relógio e caneta no bolso do paletó, fazendo um esforço enorme para pronunciar adequadamente as línguas metropolitanas, os negros não deixavam de ser macaquinhos imitando homens."(MUNANGA, 1988, p. 30). Os guetos refletidos nas narrativas de Cage estavam repletos de trabalhadores, de pessoas comuns que se ajudam e que também 
erram. Não eximem os negros da prática de crimes, mas, no entanto, não os colocavam na condição de imitadores de brancos.

Refletir sobre o universo de Luke Cage, significa percebermos vários aspectos peculiares de sua vida. E um deles encontra-se no fato de que, apesar de ter sido forjado pelos mesmos componentes químicos atribuídos ao surgimento do Capitão América (1940), o herói de aluguel não trabalhava de graça como mostra o subtítulo de suas HQs; não defendeu causas tão universais como as que foram impostas ao Capitão, mas nem por isso deixou de defender causas nobres. Trabalhou na defesa de asiáticos, negros, brancos e todos os que podiam pagar. Por vezes, até defendeu de graça os menos favorecidos, mas se utilizou de sua super força para ganhar o pão de cada dia, o que é uma atitude condenável nos super-heróis brancos.

Suas narrativas contribuíram para combater os complexos atribuídos aos negros, desde do período de colonização e no caso dos Estados Unidos, também na Guerra de Secessão (1861-1865), onde o negro foi animalizado, brutalizado e tratado com bastante violência.

As marcas ofertadas pela saga de Luke Cage são de retratar aos seus leitores não somente o submundo do crime, mas, sobretudo os guetos, norte-americanos, que passavam pelo processo de descolonização, uma vez que refletiu sobre a cultura negra e a restauração destes espaços para ajudar o herói na luta não contra super vilões, como os encontrados nas HQs de super heróis. Cage lutou contra personagens mais reais, tais como: policiais corruptos e outros criminosos que desejavam arduamente transformar os bairros negros em espaços liberados para aliciamento de homens e mulheres para o universo do crime.

Cage retrata bem o perfil do negro norte-americano visto pelo branco. Para o último, os negros continuavam sendo os colonizados e eles os colonizadores dentro do mesmo país. No entanto, o nosso anti-herói descobriu a tempo de subverter essa lógica colonizadora e de certa forma enunciada pelo discurso dos brancos como natural. Parece que o personagem aprendeu a "quebrar suas correntes de barbante", como ressaltou Memmi (1977, p. 133) ao se referir ao retrato do colonizado, e foi à luta na defesa das minorias.

As HQs de Luke Cage demonstraram a sociedade norte americana corroída por vícios de várias ordens. Ressaltaram que a violência não tinha cor e nem endereço, pelo contrário, fura barreiras e se apresenta em toda parte. Nesse sentido, Cage parece zombar da sociedade que o produziu, fazendo-nos pensar na análise de Fanon (1968) sobre o processo de descolonização quando o branco requer a razão aos colonizados, 
No período da descolonização apela-se para a razão dos colonizados. Propõem-lhes valores seguros, explicam-lhes abundantemente que a descolonização não deve significar regressão, que é preciso apoiar-se em valores experimentados, sólidos, citados. Ora, acontece que quando ouve um discurso sobre a cultura ocidental, o colonizada saca da faca de mato ou pelo menos se certifica de que a tem ao alcance da mão. A violência com que se afirmou a supremacia dos valores brancos, a agressividade que impregnou o confronto vitorioso desses valores com os modos de vida ou de pensamento dos colonizados fazem com que, por uma justa reviravolta das coisas, o colonizado ria com escárnio ante a evocação de tais valores. No contexto colonial, o colono só dá por findo seu trabalho de desancamento do colonizado quando este último reconhece em voz alta e inteligível a supremacia dos valores brancos. No período da descolonização a massa colonizada zomba desses mesmos valores, insulta-os, vomita-os (FANON, 1968, p. 32).

Percebemos que o personagem Luke Cage se utilizou da violência como forma de opressão e de libertação para si e para os demais que o contratavam. Diante de tais circunstâncias, o herói de aluguel subverteu as lógicas e revelou um mundo doente aos norte-americanos, primeiramente, e aos demais leitores de outros países onde suas aventuras foram traduzidas e comercializadas.

Cabe-nos ainda registrar que a trajetória de Cage, ao contrário de outros heróis da Marvel, foi desde do início, um projeto de construção que visou inserir personagens negros na condição de protagonista e para isso a dupla Priest e Billy Graham, ambos negros, foram fundamentais para o sucesso do personagem.

\section{CONSIDERAÇÕES FINAIS}

As Histórias em Quadrinhos - HQs - e seus heróis, habitaram e habitam, hoje em menor escala, levando em conta o advento da internet, a adolescência e juventude de muitas pessoas.

No entanto, apesar da presença contínua em papel ou virtualmente, podemos notar que o leitor espera quase sempre um herói que represente os seus anseios e no qual se sinta representado ou se reconheça. Nesse sentido, é fácil se identificar com o Superman, o Homem Aranha, o Batman, dentre outros, pois todos são um misto de homens brancos, jovens, ricos e justiceiros que estão sempre dispostos a enfrentar os bandidos em nome da lei, posto que essa é a atitude esperada de um super-herói que habita o inconsciente coletivo da humanidade. 
Heróis que voam, que pulam de prédio em prédio e que usam capas e máscaras são normalmente admitidos no hall da fama dos homens brancos. Mas, e aqueles que nascem negros e pobres e habitam a periferia da cidade ou do mundo, como é o caso de Luke Cage e do Pantera Negra? A questão que aqui se coloca para discussão é saber como Luke Cage e o Pantera Negra poderão ser salvos da condenação histórica por serem vistos apenas como complemento para uma galeria que ainda hesita em ter um herói negro, mas que tem que fazê-lo como se fosse uma política de cotas onde se requer, obrigatoriamente, a presença de heróis negros.

A criação de Luke Cage e do Pantera Negra nos anos 60 e 70 como protagonistas de histórias em quadrinhos se constituiu em um ato de coragem e rebeldia, pois a atitude de trazer para o centro heróis negros que representam ostensivamente a face da pobreza e da periferia e que têm uma trajetória longe de ser comparada a de outros heróis, quebra com os paradigmas vigentes no que concerne ao processo de colonização.

A força da colonização e da falsa bondade do colonizador, pois Fanon (1968) afirma que todo colonizador é perverso, não consegue mais conter a emergência das histórias de homens negros, pobres e periféricos que lutam por direitos iguais e também para se verem representados em uma história, mesmo que seja em quadrinhos, como sujeitos ativos, pertencentes à uma cultura e protagonistas de suas lutas. Além disso, a questão identitária de um povo é basilar para que homens e mulheres se reconheçam, se reafirmem e se inscrevam na história.

A história dos homens brancos sempre tentou encobrir a história de homens negros, utilizando-se de artifícios para desqualificá-los, como, por exemplo, considerálos feios, vagabundos, de má índole, improdutivos, criadores de caso e outros estereótipos em uma tentativa de invisibilização das ações positivas de povos negros, e não só, mas também, daqueles que de algum modo não se enquadravam modelarmente nos ditames do capitalismo e nos comportamentos sociais aceitáveis.

No meio do panorama desigual do furacão da colonização e de ações de segregação, está o herói Luke Cage. Dissemos, em um momento do texto, que Luke Cage é um herói às avessas ou um anti-herói, pois a narrativa de seu nascimento e de sua conduta perante o social destoam das trajetórias de outros heróis, mas é exatamente a face e a condição mais humana e menos heróica de Cage que são suas grandes marcas. Um herói que tem como marca um percurso comum igual a de outros homens que erram e acertam ganha, mesmo que tempos depois, a empatia do público.

Uma pergunta: Luke Cage poderá nos salvar? Assim como Chapolin Colorado, herói televisivo mexicano, de antenas vermelhas, ingênuo, a ponto de contar apenas com 
sua astúcia, que possui um corpo franzino e curvado que nem de longe lembra um superherói e que não salva ninguém com grandes feitos, Cage, no seu trajeto desordenado e contrário a Chapolin, termina por nos salvar.

Luke Cage nos salva no sentido de ser constituído como um dos heróis mais humanizados, que representa e referenda uma classe que por muito tempo esteve submersa em um mundo colonizado onde diziam não poder haver heróis, pois as periferias não geravam nada de bom e os homens negros e pobres não podiam ter alguém para se reconhecer.

Luke Cage nos salva, ainda, do perigo da história única a que se refere Chimamanda Adichie em sua conferência em julho de 2009 pela Fundação Sapling dos Estados Unidos da América, em que a autora fala da voz cultural que é entrecortada por outras vozes e histórias totalmente diferentes, o que significa que ninguém vive a mesma história.

O herói Luke Cage é a contranarrativa que faz frente a uma história que seria quase única, a do colonizador, se não fosse a sua própria história, descolonizadora. 


\section{REFERÊNCIAS:}

ADICHIE, C. O Perigo da História Única. 2014. (18m49s). Disponível em: <https:// www.ted.com $/$ talks/chimamanda_adichie_the_danger_of_a_single_story?language $=p t-$ br>. Acesso em: 01 jun. 2019.

BROMBERT, V. Em Louvor de Anti-Heróis. São Paulo: Ateliê, 2004.

FANON, F. Pele Negra Máscaras Brancas. Trad. Renato da Silveira. Salvador: EDUFBA, 2008.

FANON, F. Os Condenados da Terra. Rio de Janeiro: Civilização Brasileira, 1968.

HOBSBAWAM, E. Era dos Extremos: o breve século XX - 1914-1991. São Paulo: Companhia das Letras, 1995.

KARNAL, L. [et al.]. História dos Estados Unidos - das origens ao século XXI. São Paulo: Contexto, 2007.

KIPLING, R. The White Man's Burden. Nova York: Revista McClure's, 1899.

MEMMI, A. Retrato do Colonizado Precedido pelo do Colonizador. Rio de Janeiro: Paz e Terra, 1977.

MUNANGA, K. Negritude: usos e sentidos. 2 ed. São Paulo: Ática, 1988.

SPIVAK, G. Pode o subalterno falar? Belo Horizonte: UFMG, 2010. 